Six central themes were identified:

1. Regional aspects: Japan and the others;

2. Company policy;

3. Research and Development;

4. Cooperation between basic research and industrial research and development in Europe;

5. Demands on basic research;

6. The future.

\section{Regional Aspects}

To set the scene, an overview of the international development of magnetooptical recording was given by Professor R. Carey of Lanchester Polytechnic, Coventry. According to him Japanese companies in their plans have shared out amongst themselves the future world market leaving no space for other countries. Factories are being built, research at some companies has even been finished, yet European companies are still hesitant.

In contrast, the workshop demonstrated that "basic research" as well as "research and development" in Europe is on a par in this field of recording, comparing favourably with the USA. Most basic ideas, which have led to $R \& D$ activities in magnetic materials have been created in Europe and indeed for a long time, Europe was ahead of other countries in basic research in magnetism. What has happened in the mean time?

Three opinions were expressed:

(a) The Japanese work harder than Europeans.

(b) The Japanese are considerably more agressive (while staying polite!) than European companies in fighting for market shares. Decisions in that phase are said to be made much faster in Japan than in Europe.

(c) The technology transfer and cooperation between universities and governmental institutions and industrial companies is seen to be more intensive and more efficient in Japan and the USA than in Europe, where an "interfacial problem" seems to exist. In Europe too large a gap seems to be opened between the goals and working levels on both sides.

\section{Company Policy}

Given that R \& D in Europe is at the same level as elsewhere why do companies see problems in the development of the market and hesitate to share the optimism of Japanese companies? How can it happen, that only a few percent of the present market in magnetic recording systems and mass storage media is held by Euröpean companies, while all the rest is shared between Japan and the USA? In Europe investment in new technologies is very carefully balanced against the expected success, the overriding aim being to avoid too great a risk. If success becomes obvious, European companies will then want to enter the market. But - will it then be too late? Breaking in will present a formidable challenge.

The technical skills are there and a great number of ideas are waiting to be transformed into products. European laboratories have a large capability. If it can be concentrated, the ideas as well as the results of research combined, if a strategy can be devised, then European countries can mount a real challenge.

\section{Cooperation}

Cooperation is open to improvement. Many of the technological problems which arise in the development laboratories (like aging, corrosion, protection, etc.) are of minor interest for basic research, but they are vital for future products. This gap has to be closed. Examples can be found where cooperation is better such as in programmes like Esprit or EUREKA. There the links between European companies in R \& D and to related research institutions have proved to be possible and can be organized as successfully as in Japan or the USA. One point should be stressed: the demands of supporting European institutions are in some cases too strong. University institutions cannot in all cases follow exactly the $R$ \& $D$ lines of industrial laboratories. They need independent support for long term and efficient research. Some improvements may be possible in this area.

\section{Demands on Basic Research}

Industrial laboratories were asked to state their requirements. One of the main problems seems to be to find scientists, well trained in the problems of magnetism as there are only a few universities in Europe, giving special courses in magnetism. In some cases, industrial laboratories try to hire young scientists already trained in magneto-optics but they have little success.

A special although still incomplete list of present problems which should be investigated in basic research laboratories was presented by Dr. Heitmann of Philips Research Laboratory, Hamburg.

These could be summarized as:

- Improvement of basic knowledge;

- Magneto-optical effects in amorphous alloys;

- Control of magnetic anisotropy; Molecular field parameters

- Understanding of: write noise, thermomagnetic switching, physical limits of thermomagnetic recording;

- Direct over-write.

The three days of presenting papers and discussing the problems were found by all participants to be very fruitful and successful.

H. Hoffmann, Regensburg W. Zinn, Jülich

\title{
SQUID: State of Art, Perspectives and Applications
}

$$
\text { Rome - CNR, 22-24 June } 1988
$$

The workshop focussed on the main aspects of SQUID activity. The most important application of SQUIDs is in biomagnetism, for the recording of the magnetic field generated by the human body. By using many channels of detection the possibility is opened of creating a powerful diagnostic instrument that can map functional activity and localize diseases especially of the brain. This together with the planar gradiometer, fabricated with lithographic techniques will form the main thrust of developments in biomagnetism where multichannel devices with tens of devices working at the same time are required.

A new and fast growing field of application is in elementary particle physics for detecting weakly ionizing par- ticles, such as massive monopoles and low energy neutrinos. Digital linearization which is now becoming competitive with the more traditional analogue technique can noticeably reduce the number of wires connecting the low temperature device to the room temperature apparatus.

SQUIDs based on the new high $T_{\mathrm{c}}$ materials have already reached performances as good as those employing conventional superconducting materials of twenty years ago. They are, nevertheless, still far away from practical use because multilayer lithographic techniques are not yet available, nor even true Josephson junctions. The very low coherence length makes the task of reaching this goal very difficult. 
The area is high technology but not wide spread, because the market is still very limited. Many European industries are investing $R$ \& $D$ effort in systems for biomagnetism, but to date only one small-sized American manufacturer is selling systems.

The workshop, help in the brand new, excellent facilities of the CNR Headquarters in Rome, brought together about 40 people from industry and the academic world. All the main industries operating in the field had been invited with the result that BTI (USA), Philips (FRG), CITEC (Italy) and ITHACI (Japan) took an active part sending particularly qualified representatives. Thanks to the single subject and the small number of ly atmosphere which stimulated a lot of interesting talk. The discussions were continued outside the scheduled hours including the long, and particularly enjoyed, Italian style lunch.

P. Carelli and

A. Paoletti participants, the workshop had a friend-

\section{Latest SUN Revision}

The SUN-AMCO Commission of the International Union of Pure and Applied Physics has published the third revision of its guide to authors and editors Symbols, Units, Nomenclature and Physical Constants. In addition to up-dating, sections have been regrouped and enlarged and more specific rulings have been given on such aspects as labelling tables and graphs. The new edition is easier to follow than its predecessor, helped also by the increased type size. Our warmest thanks to the editors, E.R. Cohen and P. Giacomo.

The booklet in its familiar red cover and referred to as Document I.U.P.A.P.25 (SUN-AMCO 87-1) may be obtained from the present Secretary of the SUNAMCO Commission:

Dr. B.W. Petley

National Physical Laboratory

Teddington, Middlesex TW11 OLW, UK

The price is $£ 2.00$ including postage, but $£ 2.00$ should be added for bank charges on cheques drawn on non-British banks.

\section{History of Physics}

Consequent on a decision of Council in Dresden, the Advisory Committee on Physics Education has now incorporated a Group concerned with the use of historical approaches in the teaching of physics. The Group's first activity under the auspices of EPS will be to hold a Europhysics Study Conference in Orsay (France) from 21-28 November 1988 on the following topics:

History of concept, Reconstruction of historical experiments,

Technology and society, Physics and culture,

Physics and other science.

The day of 14 November will be devoted to contacts between the participants and secondary school teachers of physics and related sciences.
The aim of the conference is to see to what extent it might be possible to produce some common basic teaching material covering these fields which could be translated or adapted to various European languages.

Since the participation is limited to 50 , those interested should write to:

Christine Blondel

Cité des Sciences et de I'Industrie F-75930 PARIS Cédex 19

stating explicitly what their contribution might be.

For further details on the Group, contact the Secretariat in Geneva or the Chairman of the Adv. Com. on Physics Education:

Institut de Physique

B-4000 SART-TILMAN (LIEGE 1)

or at DEPIREUX @ BLIULG11.BITNET.
Joseph DEPIREUX

\section{Meetings}

\section{Late announcement:}

14-20 October 1988

Turin, Italy

2nd International Topical Meeting on Optics of Liquid Crystals: Optics and Interfacial Phenomena in LC and Polymers.

Scientific Information:

P. Taverna and L. Trossi

Physics Department, Politecnico

1-10129 Torino (Italy)

PP / 100 / ISI / 250000 LIT

\section{Postponement:}

The Conference: Physics for Industry - Industry of Physics: Solid State Physics scheduled for Krakow, Poland in September 1989 has been postponed. The new date will be announced when available.

\section{Commercial Exhibit}

The Plasma Physics Division informs us that at the 16th European Conference on Controlled Fusion and Plasma Physics to be held in Venice from 13-17 March 1989, an exhibit for commercial firms supplying materials and equipment to the field will be organized.

Commercial firms interested in displaying small sized hardware or documentation on their products are kindly invited to ask for further information from:

Mrs. M. Polidoro

ENEA

Centro Ricerche Energia Frascati

C.P. 65

I-00044 FRASCATI (Roma)

Telephone: (6) 94005309

Telecopier: (6) 94005400

Telex: $\quad 610421$ ENEA FR I

\section{Europhysics News \\ Welcomes}

\section{Readers' Letters}

Europhysics News is the official journal of the European Physical Society which comprises 29 National Societies, Academies and Group, about 4000 Individual Members and 75 Associate Members. Governing bodies of EPS are the General Meeting, Council and an elected Executive Committee responsible for detailed policy. EPS promotes the collaboration of physicists throughout Europe, organising and harmonising conferences and publications, improving physics education, encouraging physics applications, awarding scholarships to sponsored schools in Erice. EPS publishes in addition to Europhys. News, Europhysics Letters lin addition to Europhys. News, Europhysics Letters (in of Physics (in partnership with The UK Inst. of Phys.), and European Conference Abstracts. Individual Mem. bers receive Europhys. News free of charge (price to insts.: Sw.Fr. 90.-1a), Europhys. Lett. at Sw.Fr. 125. -/a insts. SW.Fr. 90. - /a), Europhys. Lett. at Sw.Fr. 125.-/a
(insts. 1050.-1, rebates on many other publications and (insts. 1050--1, rebates on many other publications and dividual Members belonging to an EPS member society is: Sw.Fr. 44-; independent members: Sw.Fr. 132.-; members of a Collaborating Society: Sw.Fr. 55..

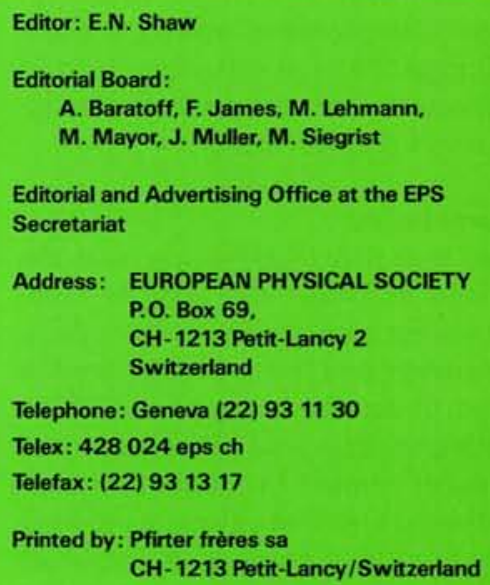

